\begin{tabular}{|c|c|c|c|}
\hline$\Omega$ & D & $\equiv$ & (2) \\
\hline Tiago Jacinto, & $\begin{array}{l}1 \text { Instituto CUF, Matosinhos, } 2 \text { Center for Research in } \\
\text { Health Technologies and Information Systems. Faculty }\end{array}$ & A. Bjerg, Krefting & anders.bjerg@gu.se \\
\hline Agnes Boots ${ }^{3}$ & $\begin{array}{l}\text { Health Iechnologeges and Intormation Systems, , a autly } \\
\text { of Medicine, Porto, Portugal. } 3 \text { Dept of Toxicology, }\end{array}$ & Research Centre, & \\
\hline Andras Bikov4 & $\begin{array}{l}\text { Maastricht University, Maastricht, The Netherlands. } \\
\text { 4Dept of Pulmonology, Semmelweis University, }\end{array}$ & Göteborgs Universitet & \\
\hline Georgia Hardavella5,6 & $\begin{array}{l}\text { Budapest, Hungary. } 5 \text { Dept of Thoracic Medicine, UCL } \\
\text { Hospital. } 6 \text { Lungs for Living Research Centre, UCL and }\end{array}$ & Göteborg, Sweden & \\
\hline Neil Saad7 & $\begin{array}{l}7 \text { National Heart and Lung Institute, Imperial College } \\
\text { London, London, UK. } 8 \text { Krefting Research Centre, }\end{array}$ & & \\
\hline Trell sadu & Department of Internal Medicie and Clinical Nutrition, & & \\
\hline Anders Bjerg ${ }^{8}$ & University of Cothenburg, Gothenburg, Sweden. & & \\
\hline
\end{tabular}

\title{
Doing Science: Oral presentations
}

In the last edition of Doing Science, we covered the creation and presentation of a poster [1], and so we shall move on to the other main way of presenting at scientific meetings: the oral presentation. Early in your career, getting your abstract accepted for an oral presentation may raise some eyebrows, your pulse and quite a few questions. After all, only $13 \%$ of the accepted abstracts were granted oral presentations at the ERS Annual Congress 2013 in Barcelona and, in 2012, the corresponding number was $14 \%$ [2]. Thus, naturally, getting accepted for an oral presentation is generally harder than getting a poster.

Rather than reflecting merely a scoring system, the two formats represent two different sides of the same coin, and present different challenges as well as opportunities. This article will serve as a walk-through for first-time presenters, and will hopefully help also more seasoned speakers improve their presentations and presentation technique.

\section{Oral presentations versus posters}

After reading the last article in the Doing Science series [1], you should be familiar with the unique features of a poster. The standard oral presentation at, for example, an ERS International Congress is 10 minutes plus 5 additional minutes for questions from the audience [3]. Thus, considerably less text can (and should!) be used in an oral presentation. The trick is to know what should be in text, in figures, merely said or, maybe most importantly, completely left out. Use the on-screen/voice dynamics to your advantage.

Now put yourself as presenter aside for a moment, and consider the audience [4] (after all, you are presenting to them). Your audience may glance upon your poster, look at other posters with similar topics, come back, skip your introduction and head straight for the conclusions, or scrutinise your methodology section meticulously; and ask you to clarify.

Your oral presentation, on the contrary, is linear [5], and you must guide the listeners through your thought process, data and conclusions. The communication is mainly one-way because questions do not interrupt the presentation and questioning time after the presentation is often very brief. Also, the format is a lot less intimate because you stand in front of a seated crowd in the semi-lit room. Being literally "on-stage" creates a distance to the audience which you will have to bridge in
As a result of an author correction, the online version of this article has been revised. 


\section{Non small cell lung carcinoma-squamous cell}

Non small cell lung carcinoma accounts for approximately $42 \%$ of primary bronchogenic carcinomas.

As you all know, its precursors are areas of dysplasia that can be found lining the entire bronchial epithelium.

The more peripheral lesions tend to cavitate more often tha the other types of non small cell lung cancer and squamous cell carcinoma tends to present initially with extended local spread while its metastases tend to present late in the clinical course of the disease.

Patients with squamous cell carcinoma are likely to present more often with obstructive symptoms than the patients with other types of non small cell lung carcinoma. These

symptoms include wheezes, shortness of breath, infection.

\section{NSCLC- Squamous Cell}

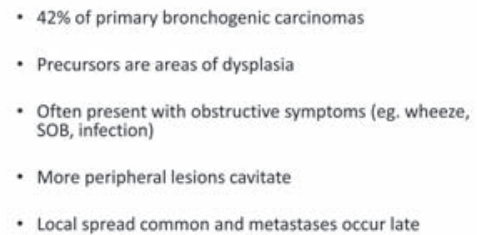

You can insert your institution's logo here
Figure 1. an example of a packed slide versus a linear one with straightforward messages. Some institutions prefer that their logo is placed in any of the upper or lower corners of the slides (Slides provided courtesy of $G$. Hardavella and N. Navani) order to get your messages through, however frightening this may seem.

All this should be considered before even ticking the Oral Presentation box when submitting your abstract. Some (often complex) data are better presented in a poster, or do not lend itself to a linear presentation with simple figures. And some presenters simply are best situated next to their poster, while others perform better on stage. We suggest, and hope, that you get the opportunity to try both.

\section{Preparing the presentation and presenting}

When preparing a presentation, you should consider several aspects. Nowadays all presentations are electronic, so be sure to familiarise yourself with the appropriate software. Microsoft PowerPoint is probably the most used software, but there are many others available. Spend some time playing around with the software of your choice; this will speed up the process of creating the slides.

The slides should be clean and clear, with high contrast colours and easy-toread and common fonts, such as Arial. The simplest, and the best, combination is a white background with black text. Some presenters prefer fluorescent text on dark backgrounds, which is however no longer necessary with today's high-quality projectors and can even be tiring to the eyes. It is very important to choose the text colours appropriately. Blue may be soothing, while red carries negative feelings and is hard to read from distance, use it very carefully. In addition, combination of red and green colors may be unsettling for those with colour blindness.

Don't include too many words in one slide (fig. 1): a maximum of eight lines of descriptive, concise bullet points. The audience should be listening to you rather than reading the slide [6]. This also prevents you from reading the displayed text out loud! Don't be afraid to use a slide with only a figure or a table. If these can summarise the work you are presenting, all the better. Just be sure to highlight the most important parts. Don't create too many slides; as a general rule of thumb, have a maximum of 1.5 slides per minute available.

Often, you will be required to upload the file with your slides prior to the presentation. In the example of the ERS International Congress, there is a speaker's room where you can do that, and run over the slides again, to make sure everything is in order. It is important to do this in good time!

Be sure to practice the speech, preferably in front of colleagues. You will get valuable feedback on your slides and presentation technique. Use short sentences and be objective, this will also help you overcome the language barrier if you are not a native English speaker. Use tone and speed changes to further highlight your main points, and play around with you presentation technique during these test runs: practice makes perfect! Speech anxiety is a common problem, and not just for first-time presenters. By practicing you can overcome anxiety. Relaxation manoeuvres (e.g. breathing slowly and deeply before and during presentation) may also be very helpful.

\section{The job is not over after presenting your last slide}

After acknowledging all the people that helped you to generate the data for your oral presentation, you will take relief from the audience's applause. You may feel that the job is done, but the chair opens up the floor to the first of probably a whole queue of questions, because your presentation was so interesting and worthwhile. Bring paper and pen to note down important questions: it both helps you on stage and afterwards (the listeners are your peers, and may be your future reviewers).

Many speakers, and first-time presenters in particular, fear this part of the oral presentation, as you have no clue what to expect. However, this ensuing discussion can also be your moment to shine, and to display your enthusiasm and knowledge. Remember that nobody is out there to get you and that all questions are meant to help your research forward. Even though you are probably still high on adrenaline from presenting, just try to relax, smile and look comfortable. 
Still, it may feel overwhelming to take these questions; especially if they come from wellestablished researchers within your field. But they too started as juniors and know the feeling of presenting one's own work on stage. In other words, try to realise that their questions are merely to tickle your scientific curiosity or to satisfy theirs. The first possibility may result in a nice "What if?" discussion regarding the application of your results or technique. Consequently, the latter option might sound more frightening but is in fact really not as nobody knows as much about your work as you do! Try to use that advantage to remain calm and confident and answer all questions from your own perspective. As long as you stick to what you know and what you did, there is no such thing as a wrong answer.

If you get stuck with a question you do not understand, owing to context, different expertise or even accent, kindly ask for a clarification, which buys you valuable time. And, sometimes admitting a knowledge gap is sincere, even relieving. Top off with a friendly smile and a "Thank you for this interesting question/suggestion" and you are good to go! You will probably enjoy the feeling of being on stage and in more control next time, and will hesitate less between ticking the "Poster" or "Oral Presentation" box!

\section{References}

1. Jacinto T, Hardavella G, Saad N, et al. Doing Science: Preparing a poster. Breathe 2013; 9: 505-507.

2. European Respiratory Society. Official web page of the European Respiratory Society. www.ersnet.org Date last accessed: January 11, 2013.

3. European Respiratory Society. Guidelines for preparing an oral presentation. 2013. Available from www. erscongress.org/images/scientific_guidelines_etc/ Guidelines_Authors_OP.pdf Date last accessed: Jan $11,2013$.

4. Collins ). Education techniques for lifelong learning. Radiographics 2004; 24: 1185-1192.

5. Nature Education. Oral presentation structure. 2013. Available from www.nature.com/scitable/topicpage/ oral-presentation-structure-13900387 Date last accessed: January 14, 2014.

6. Nature Education. Presentation slides. 2013. www. nature.com/scitable/topicpage/presentationslides-13905480 Date last accessed: January 14, 2014.
Figure 2. Recommended flow chart of a typical oral presentation.

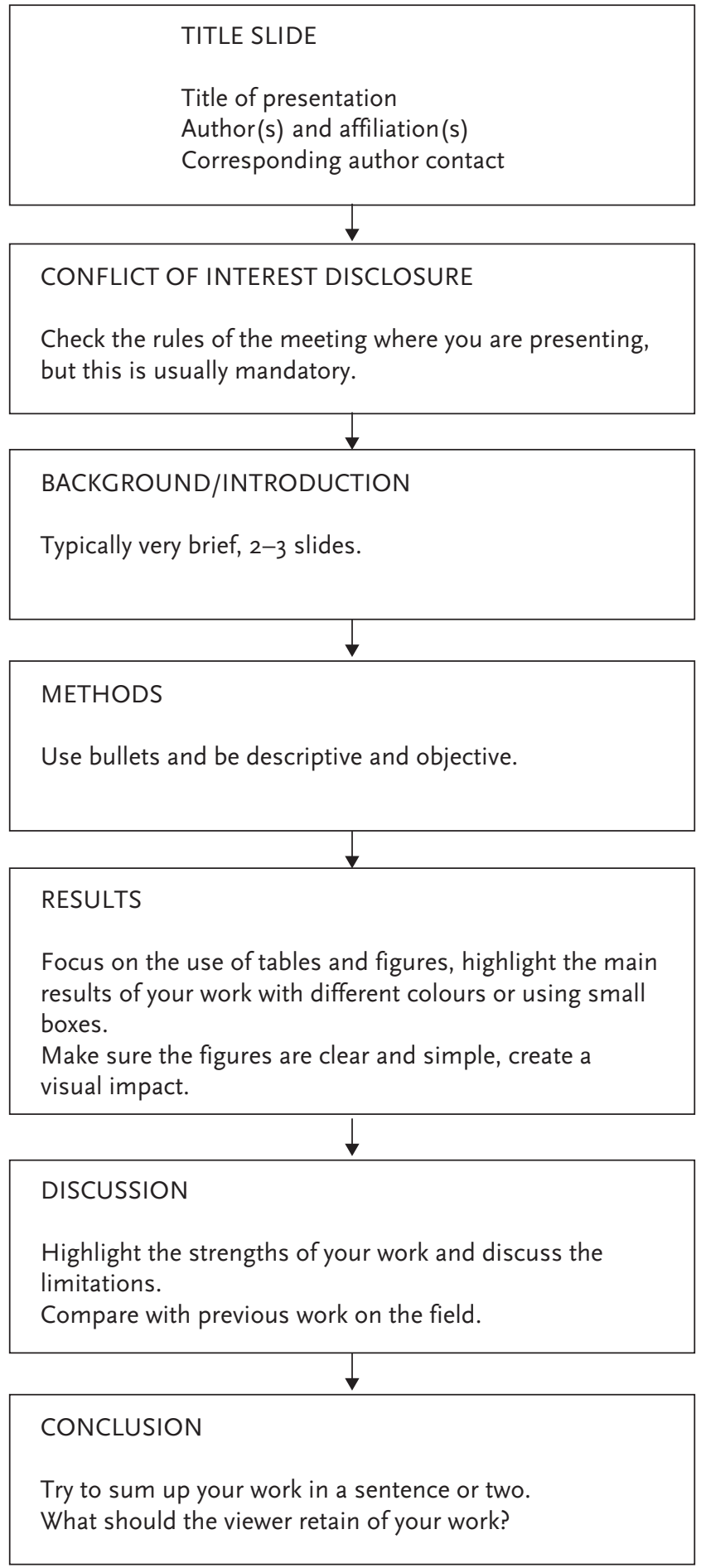

